\title{
Lead Site V10
}

National Cancer Institute

\section{Source}

National Cancer Institute. Lead Site V10. NCI Thesaurus. Code C90413.

A unipolar chest lead at which the electrode is placed over the dorsal spinous process of 7 th thoracic vertebra. 